\title{
BEHAVIOR AND DESIGN OF LATERALLY BRACED INELASTIC COMPRESSION MEMBERS
}

\author{
Eric M. Lui ${ }^{1, *}$ and Ajit C. Khanse ${ }^{2}$ \\ ${ }^{1}$ Meredith Professor and Chair, Department of Civil and Environmental Engineering, Syracuse University, \\ Syracuse, NY 13244-1240 \\ *(Corresponding author. E-mail: emlui@syr.edu) \\ ${ }^{2}$ Graduate student, Department of Civil and Environmental Engineering, Syracuse University, \\ Syracuse, NY 13244-1240
}

Received: 23 July 2007; Revised: 5 October 2007; Accepted: 10 October 2007

\begin{abstract}
This paper presents a numerical study of the inelastic response of laterally braced geometrically imperfect columns under uniform compression. The study employs the pseudo load method of inelastic analysis in which the load deflection behavior of the member is traced from the beginning of loading to ultimate failure. The compression member to be analyzed is pinned at both ends and is supported at some intermediate point by a brace. The brace is modeled as a spring and its location can vary within the length of the compression member. Although this spring brace is assumed to behave in an elastic fashion, the compression member being braced can experience inelasticity. The inelastic behavior of this braced compression member as well as the lateral bracing requirements and the effect of brace location on the ultimate strength of the braced member are investigated. Contrary to the usual design practice in which the braced point is assumed to be rigid and undergo no lateral movement, studies have shown that such a so-called fully-braced condition is rarely realized. As a result, the actual strength of the compression member will fall below its code-specified value. To ensure a safe design, due considerations must be given to the proper design of the brace. Design equations for the stiffness and strength of a brace required to develop at least $90 \%$ of this code-specified design compressive strength for the braced member are proposed.
\end{abstract}

Keywords: Compression members; bracing; inelastic behavior; geometrical imperfection; instability

\section{INTRODUCTION}

The nominal design strength $P_{n}$ of a compression member is a function of its unbraced length, support conditions, cross-section and material properties, and any geometrical and material imperfections that are present in the member. Although the behavior of centrally loaded geometrically imperfect inelastic compression members has been extensively studied and documented (see for example, Bleich [1], Bjorhovde [2], Galambos [3]), the study of such members with lateral braces is mostly restricted to elastic behavior (Winter [4], Timoshenko and Gere [5], Urdal [6], Mutton and Trahair [7], Brush and Almroth [8], Trahair and Nethercot [9], Lutz and Fisher [10], Nair [11], Plaut [12], Plaut and Yang [13], Zhang, et al. [14], Wang and Nazmul [15]). In the event that inelasticity is considered, the investigation is limited to cases with equally spaced braced points (Pincus [16], Kitipornchai and Finch [17], Ales and Yura [18], Clarke and Bridge [19], Gil and Yura [20]).

For a pinned-pinned geometrically perfect elastic column braced at midpoint by an elastic spring, the theoretical relationship between the column critical load $P_{c r}$ and the brace stiffness $k_{s}$ is given by Timoshenko and Gere (1961) as

$\frac{k_{s} L}{P_{e}}=\frac{2 \pi\left(\sqrt{\frac{P_{c r}}{P_{e}}}\right)^{3}}{\frac{\pi}{2} \sqrt{\frac{P_{c r}}{P_{e}}}-\tan \left(\frac{\pi}{2} \sqrt{\frac{P_{c r}}{P_{e}}}\right)}$

where $P_{e}=\pi^{2} E I / L^{2}$ is the Euler buckling load of the column. This relationship is shown 
graphically in Figure 1. It can be seen that $P_{c r}$ increases almost linearly with $k_{s}$ until the brace stiffness reaches a limiting value of $16 P_{e} / L$ or $2 P_{e s} / l$, where $P_{e s}=\pi^{2} E I / l^{2}$ is the segment Euler load, and $l=L / 2$ is the unbraced length (i.e., distance between braced points) of the column. At this limiting value, referred to as the ideal brace stiffness, the buckling load reaches a cut off value of $4 \pi^{2} E I / L^{2}$. This value represents the buckling load that corresponds to the second buckling mode of the pinned-pinned column. When the stiffness of the brace is less than the ideal brace stiffness, the column will buckle in a symmetric mode with lateral displacement occurring at the braced point. However, once the ideal brace stiffness is reached, the column will buckle in an antisymmetric mode with no lateral displacement occurring at the braced point. The condition under which this occurs is called full bracing. At full bracing, the column will behave as if a rigid support were placed at the braced point.
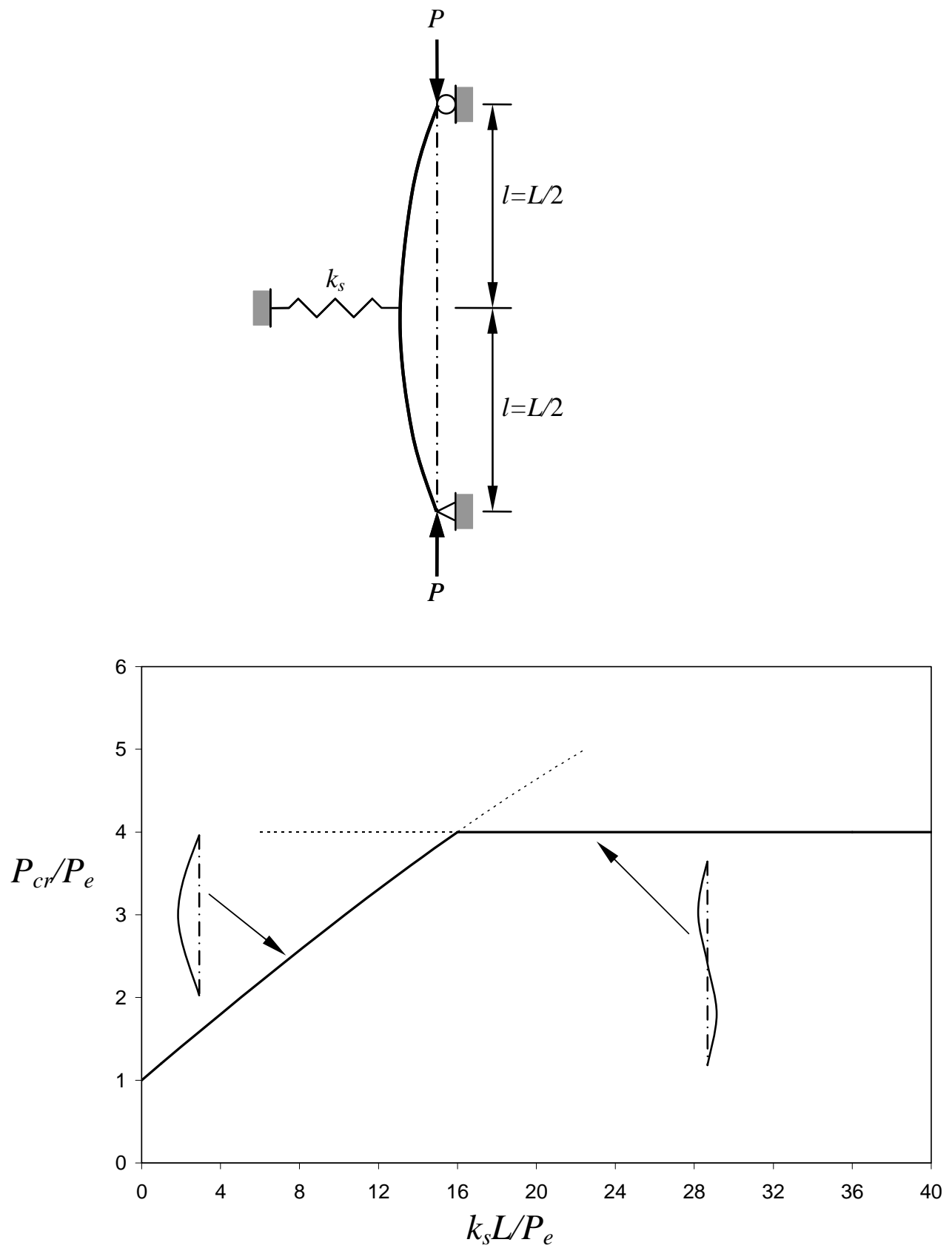

Figure 1. Behavior of a Centrally Braced Elastic Column 


\subsection{Winter's Model}

For purpose of design, the ideal stiffness for a geometrically perfect elastic column can be calculated using a simple mechanistic model shown in Figure 2a (Winter [4]). The model consists of two rigid links hinged together at the braced point and supported by a translational spring. By drawing a free body diagram of one of the rigid links in its deflected configuration and summing moment about the braced point, it can be shown that $k_{s}=2 P / l$. The ideal braced stiffness is obtained by replacing $P$ by $P_{e s}$ in the preceding equation. The Winter model can be extended to columns with equally spaced multiple braced points as well as for columns with unequally spaced braced points (Yura [21]). The model works as long as the locations of the hinges joining the rigid links coincide with the natural buckling node points of the real column. In other words, the Winter approach is valid only if the critical load of the column $\left(P_{c r}\right)$ is equal to the Euler load of the longest segment of the column $\left(P_{e s}\right)$. This condition is often violated for columns with unequally spaced braced points. $\quad P_{c r}$ for these columns are not equal to the Euler load of the longest segment because the shorter segments tend to restrain the longer segments at buckling. More importantly, it has been shown by Plaut [12] that a fully-braced condition (i.e., no lateral movement at the braced point) can not be attained for these columns using the ideal braced stiffness calculated using the Winter's model. To reach the fully-braced condition, the brace stiffness has to be unrealistically high.

\subsection{Geometrically Imperfect Columns}

Even for columns with equally spaced braced points, Winter noted that the required brace stiffness was appreciably higher than the ideal brace stiffness because of the presence of geometrical imperfections in the columns. The initial out-of-straightness present in real columns means lateral deflection will occur at the braced point as soon as the load is applied to the column. This deflection and hence the brace force increase as the column load increases. The deflection and brace force will be exceedingly high at incipient instability of the column unless a brace stiffness much higher than the ideal brace stiffness is used. To account for the effect of geometrical imperfections, the model in Figure 2a was modified to include an initial deflection $d_{0}$ in the system as shown in Figure 2b. Again, by drawing a free body diagram of one of the rigid links in its deflected configuration and summing moment about the braced point, an equation for the required brace stiffness can be written as

$k_{s, r e q^{\prime} d}=\frac{2 P}{l}\left(1+\frac{d_{0}}{d}\right)$

At incipient instability $P=P_{e s}$. Substituting $P_{e s}$ for $P$ in the above equation, and realizing that $2 P_{e s} / l$ is the ideal brace stiffness for a pinned-pinned column with a central brace, Eq. (2) can be written as

$k_{s, \text { req'd }}=k_{s, \text { ideal }}\left(1+\frac{d_{0}}{d}\right)$

If the brace behaves elastically, the force in the brace can be calculated from the equation

$F_{s}=k_{s, \text { req'd }} \cdot d=k_{s, \text { ideal }}\left(d+d_{0}\right)$ 
Eqs. 3 and 4 form the basis for the design requirements for the stiffness and strength of discrete braces that are equally spaced along the length of the column (Galambos [3], McGuire [22], Salmon and Johnson [23], CSA [24]).

Using an elastic pinned-pinned column with different initial imperfection shapes braced at midpoint by a spring brace, Plaut [12] showed that Eq. (3) would be inadequate and proposed the following equation for the required brace stiffness

$$
k_{s, \text { req'd }}=k_{s, \text { ideal }}\left(1+1.5 \frac{d_{0}}{d}\right)
$$

The inadequacy of Eq. 3 is due to the assumption of zero moment at the braced point when in reality a moment is present as a result of column out-of-straightness. If the design stipulates that the additional deflection $d$ is not to exceed the initial deflection $d_{0}$, Eq. 5 gives a required brace stiffness that is $25 \%$ higher than that computed using Eq. 3.

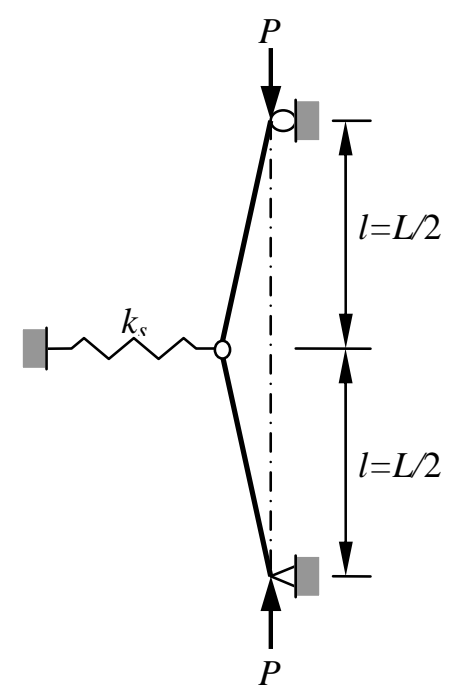

(a) Without Initial Geometrical Imperfections

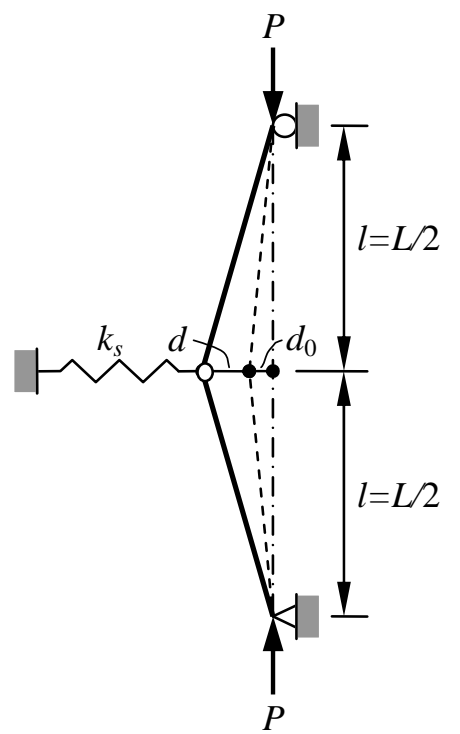

(b) With Initial Geometrical Imperfections

Figure 2. Winter’s Braced Column Models 


\subsection{Unequally Spaced Braces}

If the brace is not located at the midpoint of the pinned-pinned column, the fully braced condition can be attained only if the brace stiffness is unrealistically high. That is, $k_{s, \text { ideal }}$ has to approach that of a rigid support to prevent lateral movement from occurring at the brace point. For this situation, it is more logical to express the required brace stiffness as a function of the expected load-carrying capacity of the column, rather than as a function of the ideal brace stiffness. To this end, Plaut [12] proposed the following equation

$k_{s, r e q^{\prime} d}=\frac{P L}{\left(L-a_{1}\right) a_{1}}\left(1+1.5 \frac{d_{0}}{d}\right)$

where $P$ is the column load (which is less than $P_{\text {rigid }}$, where $P_{\text {rigid }}$ is the load-carrying capacity of the column if a rigid support is placed at the location of the brace), $a_{1}$ is the distance from one end of the column to the location of the brace, and $L$ is the length of the column. Eq. 6 was developed based on an analysis of a pinned-pinned elastic column supported by a spring brace. Other equations for $k_{s, r e q ' d}$ for this condition are given by Urdal [6] and Stanway et al. [25].

\subsection{Column Inelasticity}

Most columns in real structures exhibit inelastic behavior at their design strengths. By introducing a rotational spring to the Winter's model at the braced point to simulate the flexural rigidity effect of the column and by using the tangent modulus concept, Pincus [16] showed that the required brace stiffness was higher for an inelastic than an elastic column. This argument was supported by Trahair and Nethercot [9], but disputed by Ales and Yura [18] and Gil and Yura [20]. In this paper it will be shown that as long as the applied load is less than $70 \%$ of the maximum load-carrying capacity of the column, the required brace stiffness to attain a certain load level is virtually the same regardless of whether the column is elastic or inelastic. However, it should be noted that the maximum load-carrying capacity of an inelastic column is often lower than that of an elastic column. The required braced stiffness to attain the maximum load-carrying capacity for the two columns will therefore be different.

\section{METHOD OF ANALYSIS}

The model used for the numerical analysis is shown in Figure 3. The compression member of length $L$, pinned at both ends, is braced at an intermediate point by a spring brace located at a distance $a_{1}$ from one of the supports. The stiffness of the brace is denoted as $k_{s}$. In this study, $k_{s}$ is assumed to be a constant although under certain circumstances the brace stiffness can exhibit nonlinear behavior (Kitipornchai and Finch [17]). The use of a constant brace stiffness is justified here because the amount of deformation experienced by the brace is relatively small. To simulate geometrical imperfections that are unquestionably present in a real member, an initial crookedness in the form of a half sine curve is introduced to the model. The maximum out-of-straightness of the member is taken as $0.001 L$ at midspan. The initial deflection from the member chord due to member crookedness is denoted as $d_{0}$, and any additional deflection due to member buckling is denoted as $d$.

A load-deflection analysis using the pseudo load method of inelastic analysis (Lui and Zhang [26]) was employed to obtain maximum compressive strengths $P_{\max }$ of the member for different values of 
brace stiffness $k_{s}$, slenderness parameter $\lambda$ (where $\lambda=\frac{K L}{r \pi} \sqrt{\frac{F_{y}}{E}}$, in which $K$ is the effective length factor - set equal to 1 for a pinned-pinned column, $L$ is the column length, and $r, F_{y}$ and $E$ are the radius of gyration, yield strength and modulus of elasticity, respectively), and non-dimensional brace location $a_{1} / L$. An incremental iterative method was used to trace the nonlinear load-deflection curve and $P_{\max }$ was obtained as the peak point of this curve. The nonlinear behavior of the system is attributed to both geometrical and material effects. In the pseudo load method of inelastic analysis, geometrical nonlinearity is accounted for by the application of pseudo in-span and member end shears to the structure and material nonlinearity is accounted for by the use of a predetermined cross-section moment-curvature-thrust relationship in forming the member stiffness matrix and in calculating the pseudo loads. Details of the method are given in Lui and Zhang [26] and will not be repeated here. However, it is important to note that because the pseudo-load method is a load control method, it is not capable of tracing the descending branch of the load-deflection curve. As a result, the post-buckling behavior of the system can not be evaluated in this study. Furthermore, it should be pointed out that depending on the stiffness and location of the brace, the braced column may fail in a symmetric or an asymmetric mode as shown in Figure 4. For instance, a pinned-pinned unbraced column will fail in a symmetric mode (in the form of a half sine wave) while a fully-braced column will fail in an asymmetric mode when a sufficiently stiff brace is provided at the midpoint of the column. From these two extreme conditions it can be inferred that there is a transitional brace stiffness at which the failure mode will switch from one of symmetrical to one of asymmetrical. In a numerical analysis, a symmetrical model will always produce symmetrical solution even though the solution may not be the controlling one. In order to generate results for the asymmetric mode, small disturbing forces were applied in the transverse direction to guide the column to fail in this mode. Based on a series of numerical analyses, it was found that a disturbing force of magnitude $0.001 P$ (where $P$ is the column axial force) applied in an asymmetrical pattern at six evenly spaced points along the length of the column would provide the desired results. Thus, to obtain the correct $P_{\max }$ when the brace was at or near the midpoint of the column, two analyses were performed. One would give a symmetrical solution and the other would give an asymmetrical solution. The lower of the two $P_{\max }$ was then taken as the ultimate capacity of the braced member. If the location of the brace is away from the midpoint of the column, the correct failure mode will automatically be obtained and no transverse disturbing forces are needed in the numerical analyses to arrive at the correct solution.

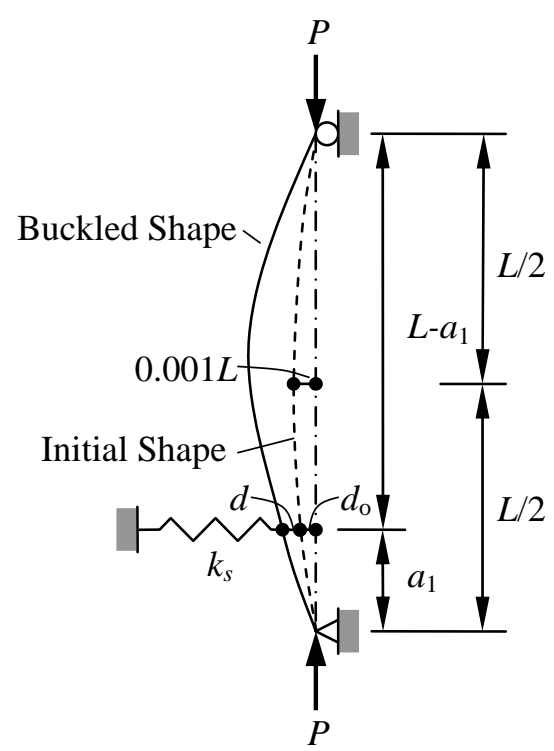

Figure 3. Geometrically Imperfect Braced Column Model 


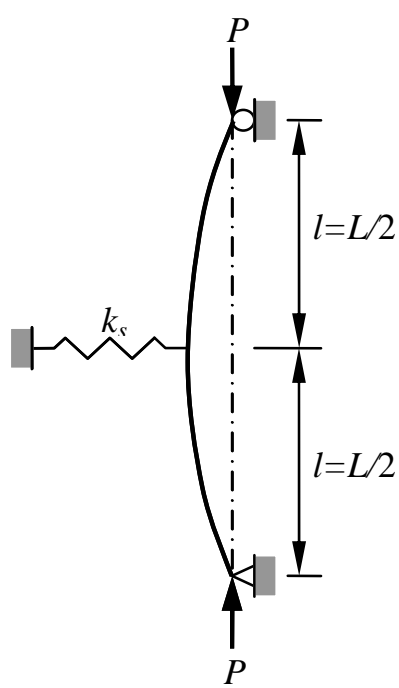

Symmetric

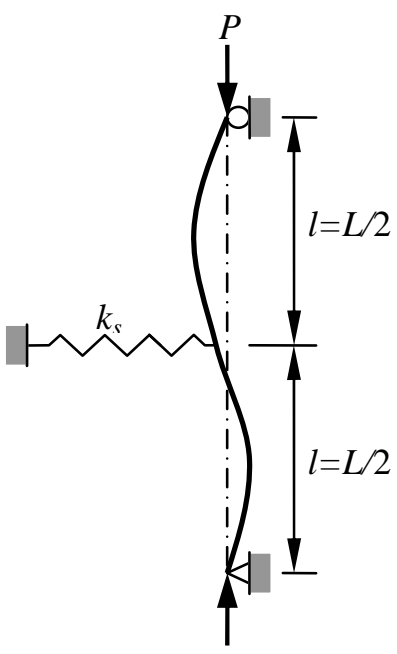

Asymmetric

Figure 4. Symmetric and Asymmetric Buckling Modes

\section{VERIFICATION STUDIES}

To validate the method of analysis discussed in the preceding section, numerical results obtained using the pseudo load method are compared with results reported in the literature. Two comparisons will be made: The first is a comparison of critical loads for an elastic column braced by an elastic spring to show the effect of the brace location on the column critical load. The second is a comparison of ultimate strengths of a centrally-braced inelastic column to show the effect of brace stiffness on the column compressive strength.

\subsection{Geometrically Perfect Elastic Column Braced by an Elastic Spring}

The theoretically solution for a geometrically perfect elastic column braced by an elastic spring located at an arbitrary location within the length of the column was given by Timenshenko and Gere [5]. The results, obtained using an eigenvalue analysis, were reported by Plaut and Yang [13]. Numerical values for the nondimensional critical load $P_{c r} / P_{e}\left(=P_{c r} L^{2} / \pi^{2} E I\right)$ plotted as a function of the nondimensional brace stiffness $k_{s} L / P_{e}\left(=k_{s} L^{3} / \pi^{2} E I\right)$ at various brace locations $a_{1} / L$ are shown in Figure 5. The solid lines in the figure represent theoretical results and the diamond markers in the figure represent numerical results generated using the pseudo load method. As can be seen, excellent correlation is observed between the theoretical and numerical results.

\subsection{Geometrically Imperfect Column Braced by an Elastic Spring}

A pinned-pinned geometrically imperfect column with various values of segment slenderness parameter $\lambda_{l}=\frac{K l}{r \pi} \sqrt{\frac{F_{y}}{E}}$ (where $K l$ is the effective length of the column segment between braced points, $r$ is the radius of gyration, $F_{y}$ is the yield stress, and $E$ is the modulus of elasticity of the material) braced by a centrally placed spring brace was analyzed by Clark and Bridge [19] using a plastic zone method of inelastic analysis. Both the symmetric and asymmetric modes of failure were investigated. The results for the nondimensional ultimate strength $P_{\max } / P_{e}$ of the column reported by Clark and Bridge [19] are compared in Table 1 with those generated using the pseudo load method. It can be seen that the results compared quite well with each other. 


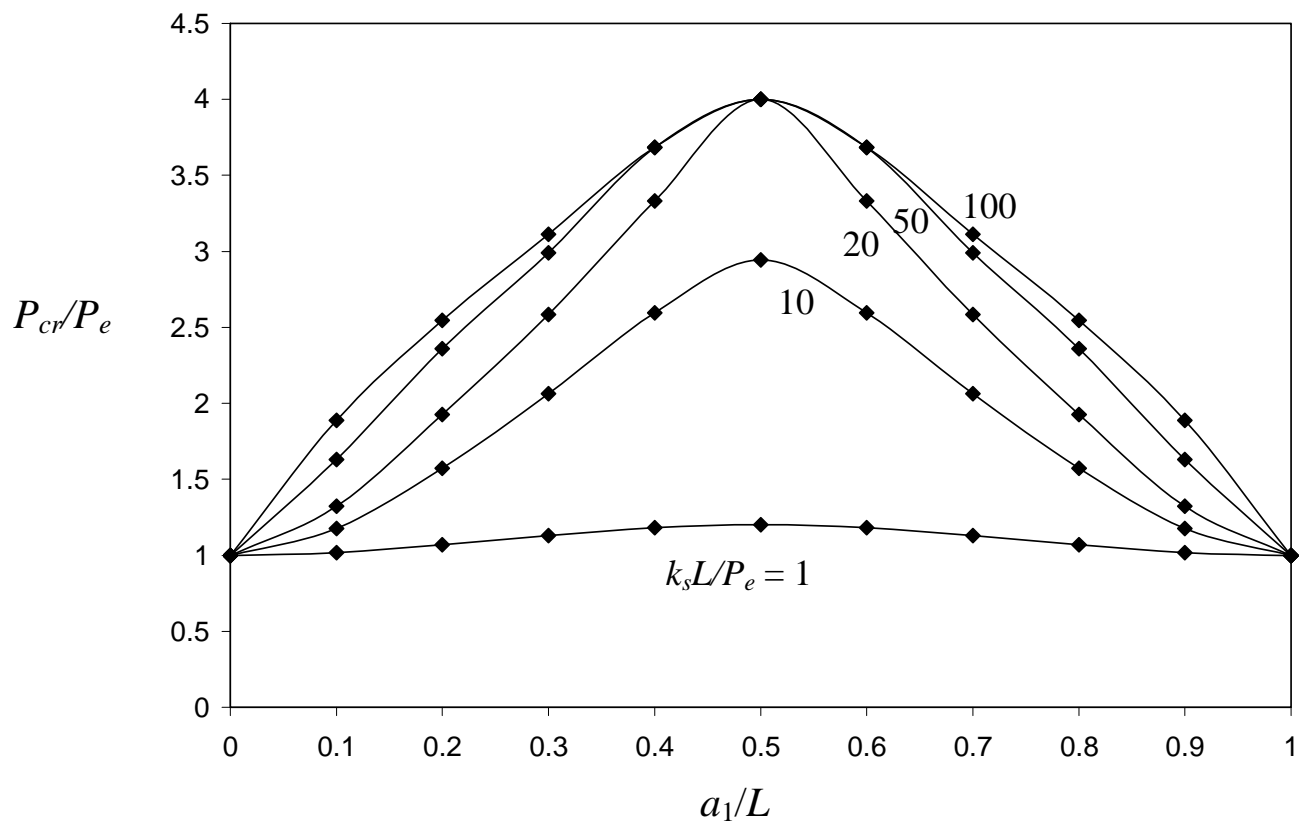

Figure 5. Comparison of Numerical Results with Theoretical Results

Table 1. Comparison of $P_{\max } / P_{e}$ for a Braced Geometrically Imperfect Inelastic Column

\begin{tabular}{|l|l|l|l|l|l|l|l|l|}
\hline & \multicolumn{2}{|c|}{$\lambda_{l}=0.5$} & \multicolumn{2}{c|}{$\lambda_{l}=0.75$} & \multicolumn{2}{c|}{$\lambda_{l}=1.0$} & \multicolumn{2}{c|}{$\lambda_{l}=2.0$} \\
\cline { 2 - 9 } & Sym. & Asym. & Sym. & Asym. & Sym. & Asym. & Sym. & Asym. \\
\hline $\begin{array}{l}\text { Clarke } \\
\text { and } \\
\begin{array}{l}\text { Bridge } \\
{[19]}\end{array}\end{array}$ & 0.92 & 0.89 & 2.0 & 1.8 & 3.1 & 2.6 & 6.5 & 3.7 \\
\hline Present & 0.948 & 0.886 & 1.98 & 1.72 & 3.12 & 2.52 & 6.56 & 3.65 \\
\hline Error & $3 \%$ & $-0.45 \%$ & $-1 \%$ & $-4.4 \%$ & $0.65 \%$ & $-3.1 \%$ & $0.92 \%$ & $-1.4 \%$ \\
\hline
\end{tabular}

\section{NUMERICAL STUDIES}

All analyses reported herein were carried out using the following material properties: $E=29,000$ ksi $\left(200 \times 10^{3} \mathrm{MPa}\right)$, and $F_{y}=36 \mathrm{ksi}(248 \mathrm{MPa})$ or $50 \mathrm{ksi}(345 \mathrm{MPa})$. Slenderness parameter $\lambda$ that varies from 0.5 to 4 , brace location $a_{1} / L$ that varies from 0.125 to 0.5 , and nondimensional brace stiffness $k_{s} L / P_{e}$ that varies from 6 to 100 , were used in the parametric study. The pseudo load method was used to generate load deflection curves for various combinations of column slenderness, brace stiffness and brace location. The results are presented in the following sections.

\subsection{Effects of Brace Location and Brace Stiffness}

Figures 6a-d depict graphically how brace location and stiffness affect the maximum load-carrying capacity of the braced column. Four observations can be made from these figures:

1. For a given brace stiffness, the maximum column strength is obtained when the brace is located at the midpoint of the column. There is a reduction in column strength when the brace is moved away from the midpoint. This observation is consistent with the general knowledge that bracing is the most effective when administered at a point where the lateral deflection of the braced member is a maximum at incipient instability. 
2. The reduction in column strength is a function of the slenderness parameter. The reduction in $P_{\max } / P_{e}$ is less pronounced when $\lambda$ is low. This can be seen readily in Figure $7 \mathrm{a}$ and $\mathrm{b}$ in which the variation of $P_{\max } / P_{e}$ is plotted against brace location for four values of $\lambda$. Regardless of the brace stiffness, $P_{\max } / P_{e}$ does not appear to vary significantly for $\lambda=1$, but noticeable change in $P_{\max } / P_{e}$ is observed for $\lambda=4$. This observation suggests that $P_{\max } / P_{e}$ is less sensitive to the location of the brace for shorter columns or columns that are more likely to experience inelasticity.

3. Returning to Figure 6 , when $a_{1} / L=0.5$ (i.e., when the brace is located at the midpoint of the column), the data points for $P_{\max } / P_{e}$ tend to collapse toward a stationary value when $k_{s} L / P_{e}$ reaches or exceeds a certain value. This value of brace stiffness is what was referred to earlier at the ideal brace stiffness. The ideal brace stiffness occurs only for the case of a centrally braced column. Because no stationary value for $P_{\max } / P_{e}$ exists when the brace is not placed at the midpoint of the column, the concept of ideal brace stiffness does not apply to these cases.

4. Although no stationary value exists for $P_{\max } / P_{e}$ when $a_{1} / L \neq 0.5$, the variation of $P_{\max } / P_{e}$ with brace stiffness for a given brace location is less pronounced for small $\lambda$ than for large $\lambda$. This observation suggests that $P_{\max } / P_{e}$ is less sensitive to brace stiffness for shorter columns or columns that are more likely to experience inelasticity.
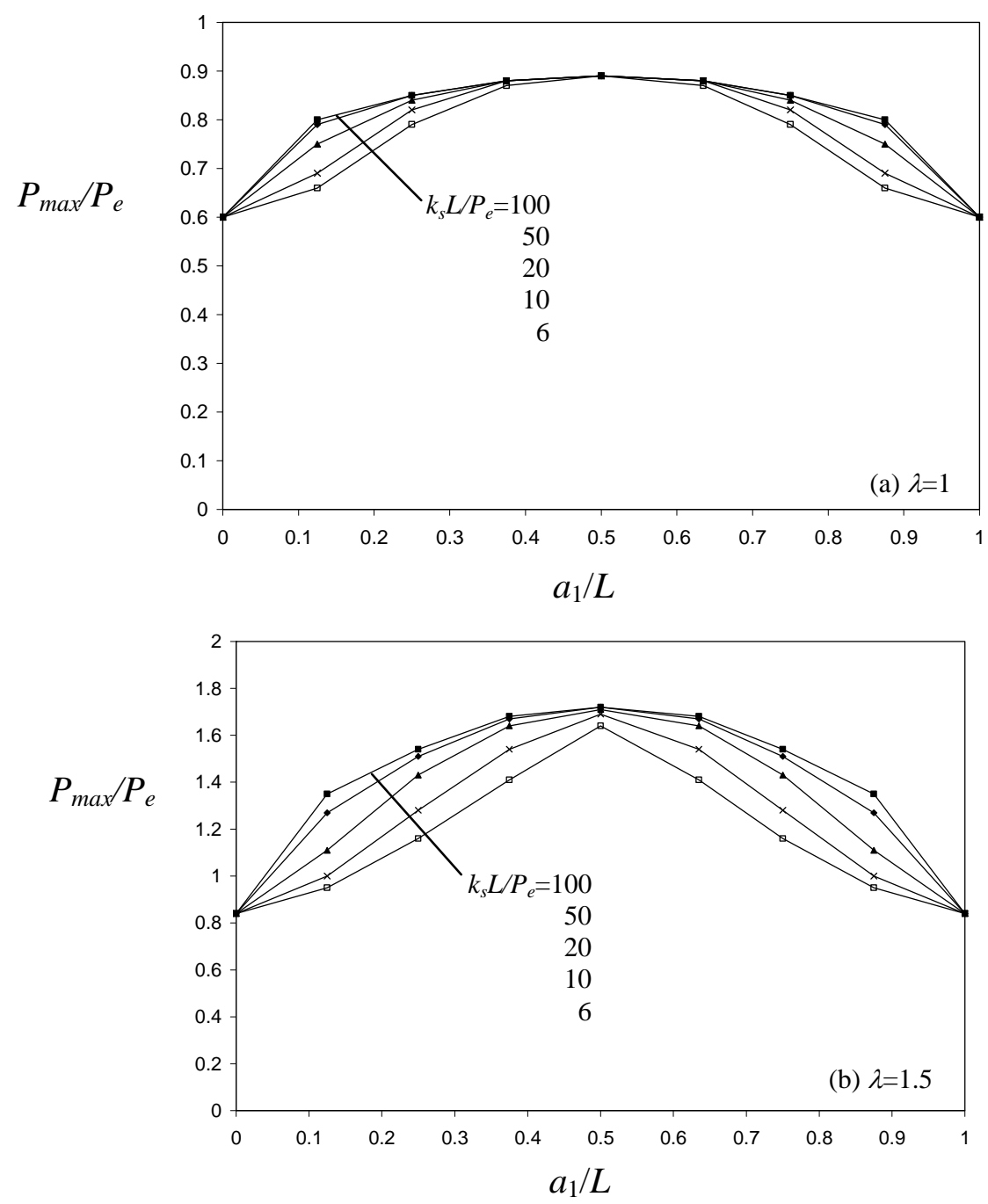

Figure 6. Effects of Brace Location and Stiffness on $P_{\max }$ 

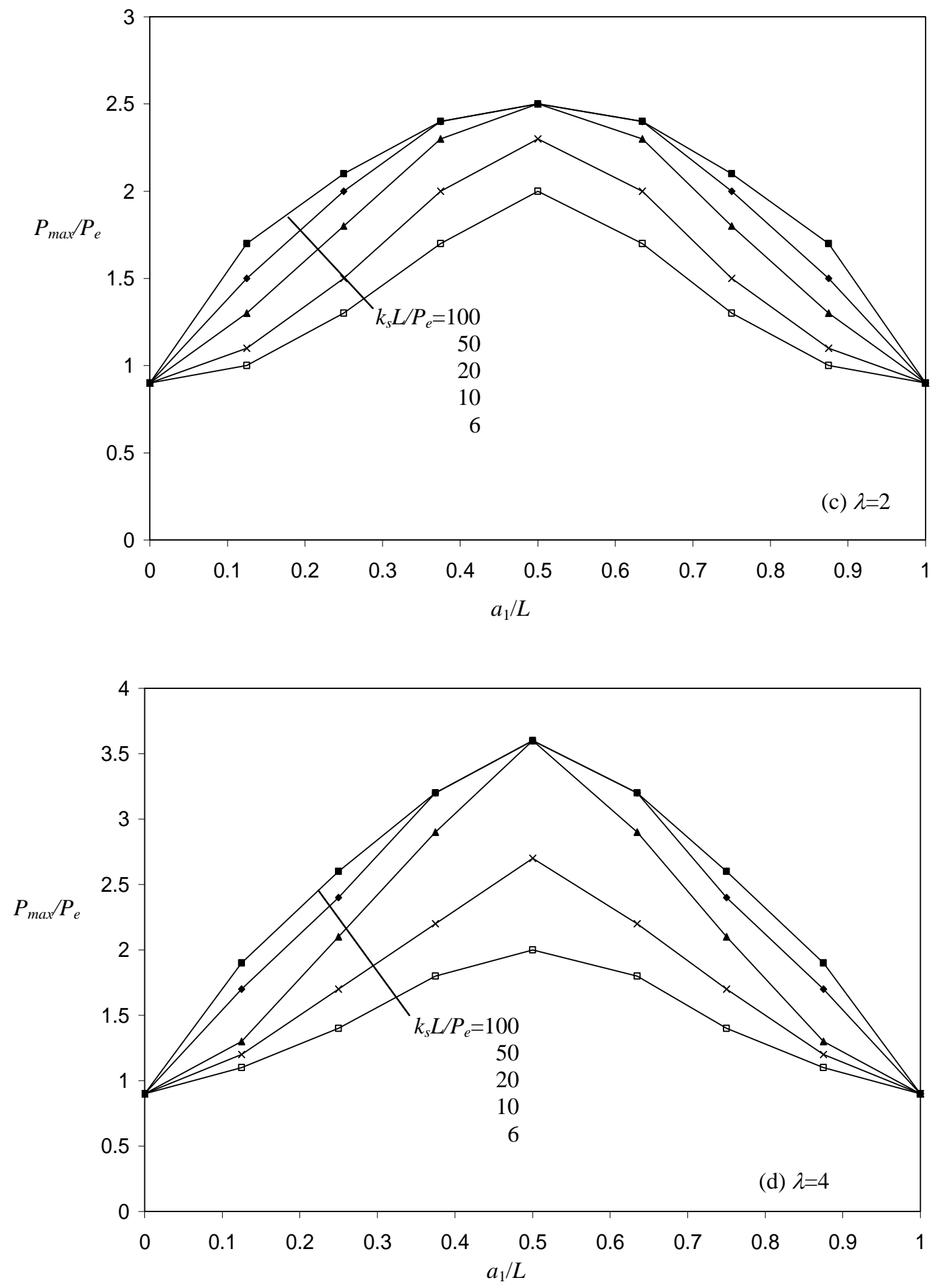

Figure 6 (Cont'd). Effects of Brace Location and Stiffness on $P_{\max }$ 

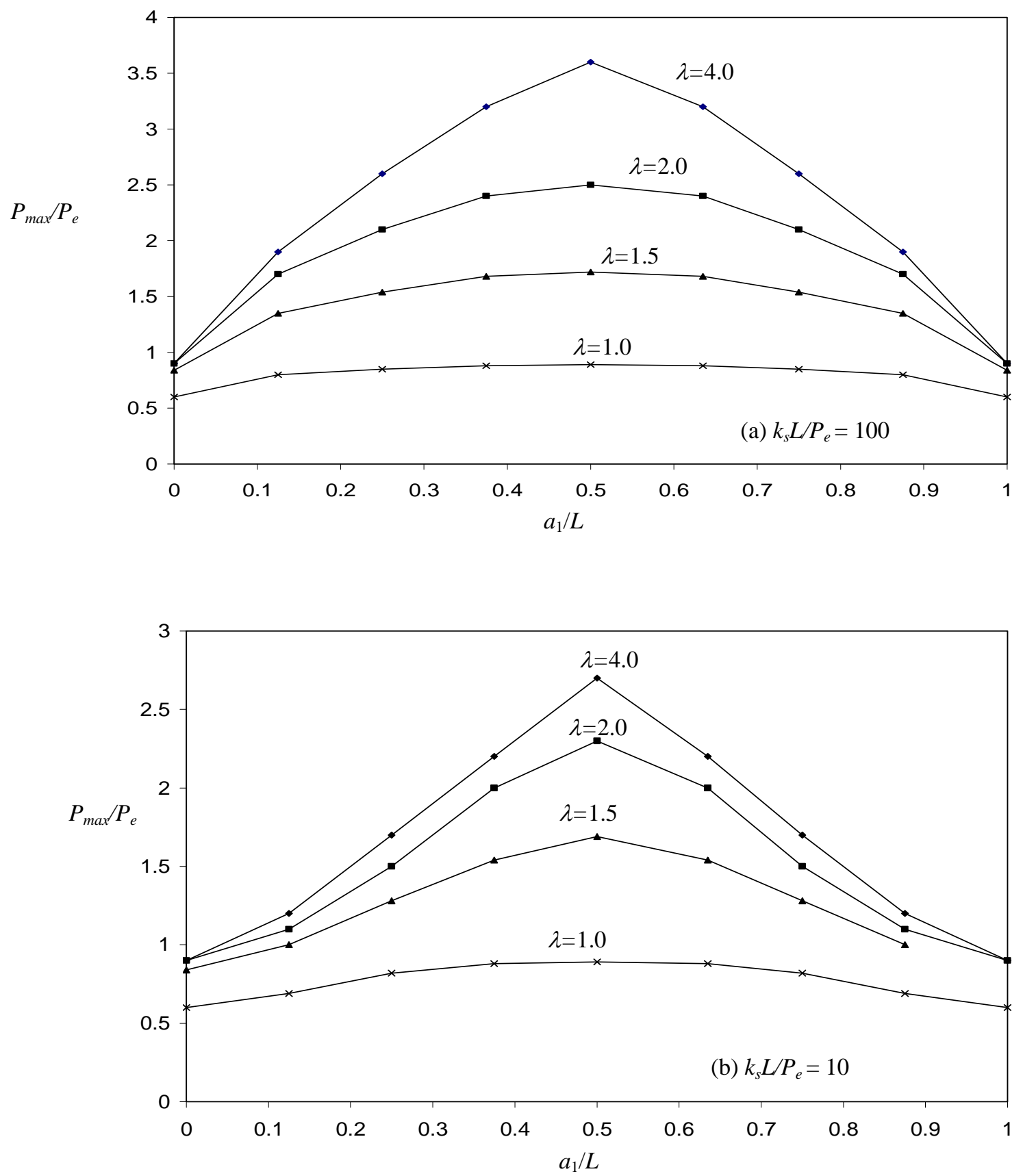

Figure 7. Effect of $\lambda$ on $P_{\max }$ 


\subsection{Effect of Column Inelasticity}

It has been shown in the preceding section that the effects of brace location and brace stiffness on $P_{\max } / P_{e}$ are less pronounced when $\lambda$ is small (i.e., when inelasticity is involved). A somewhat different but related question is: In order to reach a certain column load $P$ where $P<P_{\max }$, is a higher brace stiffness required for an inelastic column when compared to an elastic column? Based on the study by Pincus [16], the answer to the above question is yes. However, studies by Ales and Yura [18], and Gil and Yura [20] have disputed Pincus's assertion. Intuitively, one might be inclined to think that once inelasticity sets in, the flexural rigidity of the column will decrease and so a higher brace stiffness is required for the column to reach a given $P$. Nevertheless, from the load deflection curves that were generated in this study, it can be concluded that no additional brace stiffness is required for an inelastic column to attain a given value of $P$ as long as $P$ is less than about $0.70 P_{\max }$, where $P_{\max }$ is the maximum inelastic load capacity of the braced column.

Representative samples of load deflection curves are shown in Figures 8a and b. It can be seen that regardless of the brace location and brace stiffness, the load deflection curves of the elastic and the inelastic columns are quite comparable except when $P$ reaches about $70 \%$ of $P_{\max }$. From there on, the inelastic load deflection curves start to deviate from their elastic counterparts. This deviation occurs when yielding commences on the extreme compression fiber of the cross-section, and the load level of $0.70 P_{\max }$ at which this deviation occurs roughly corresponds to a maximum compressive residual stress of $0.3 F_{y}$ present in most hot-rolled sections. Since the deviation of the inelastic load deflection curve from its elastic counterpart does not occur until $P / P_{\max } \geq 0.70$, it can be concluded that as long as $P<0.70 P_{\max }$, the required brace stiffness is independent of the state of the material. However, when $P \geq 0.70 P_{\max }$, additional deflection will be experienced by the inelastic column and a higher brace force will result.

\subsection{Effect of the Form of Initial Out-of-Straightness}

Based on an elastic analysis, Plaut [12] has demonstrated that the form of initial out-of-straightness of the braced member has an effect on the magnitude of displacement, and hence the brace deflection and brace force of the system. According to Plaut [12], for the same maximum initial deflection $d_{0, \max }$ (taken as $0.001 \mathrm{~L}$ ) at midspan of the column, an initial out-of-straightness in the form of a parabola given by the equation

$d_{0}=d_{0, \max } \frac{4 x}{L}\left(1-\frac{x}{L}\right)$

yields slightly larger central deflection and larger brace deflection and brace force than that of a half-sine wave given by the equation

$d_{0}=d_{0, \max } \sin \frac{\pi x}{L}$

However, the present study, which is based on an inelastic analysis, has shown that this effect is rather negligible. A comparison of the load deflection curves for two initial out-of-straightness shapes: sinusoidal and parabolic are shown in Figures 9a and b. Regardless of the brace location and brace stiffness, the two load deflection curves differ very little. In fact, they almost overlap each other regardless of the brace location and column slenderness. For design purpose, these slight discrepancies can practically be ignored. 

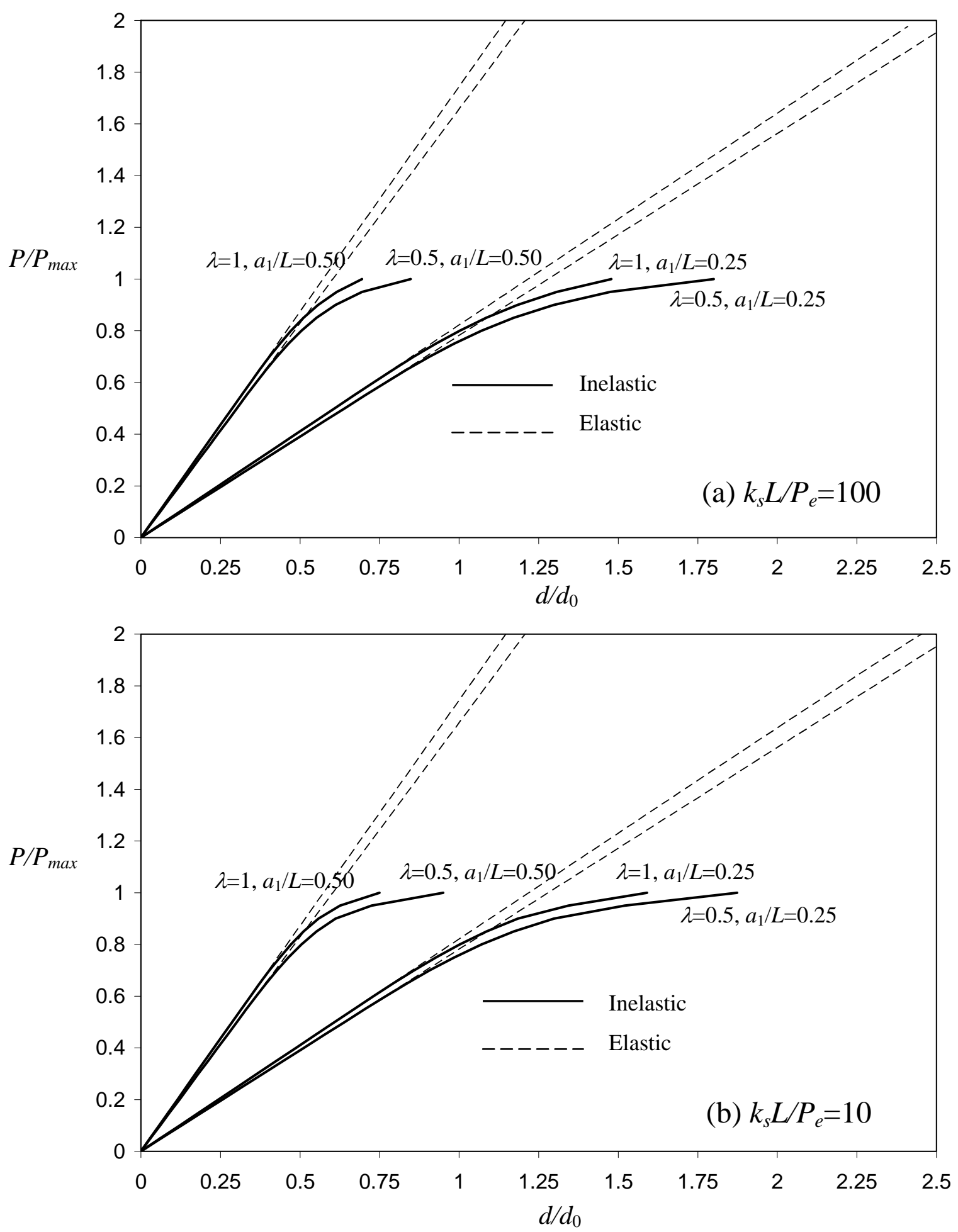

Figure 8. Comparison of Elastic and Inelastic Behavior 

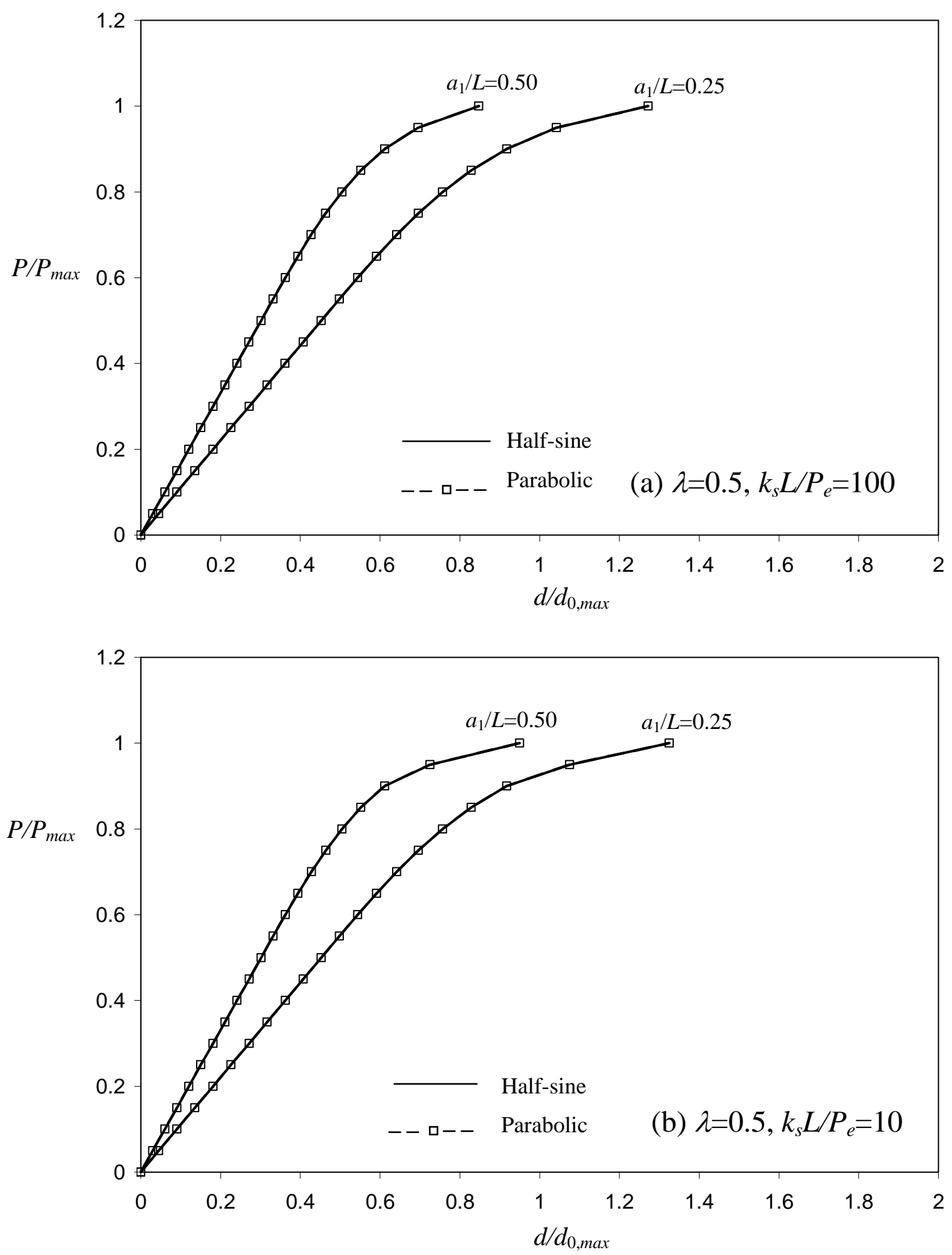

Figure 9. Effect of Different Initial Out-of-straightness Shapes 


\subsection{Effect of Brace Stiffness on Column Deflection}

When a geometrically imperfect braced column with an initial deflection of $d_{0}$ measured at the braced point is loaded by a compressive axial force $P$, it experiences an additional deflection of $d$. This deflection is a function of the column slenderness, brace stiffness, brace location and $P$. Figures 10a-f show some representative plots of the deflection ratio $d_{0} / d$ as a function of the non-dimensional brace stiffness $k_{s} L / P_{e}$ for various values of $P / P_{\text {rigid, }}$, three slenderness parameters $(\lambda=1,1.5,2)$, and two brace locations $\left(a_{1} / L=0.25,0.50\right) . \quad P_{\text {rigid }}$ is the compressive strength of the column when the brace stiffness is infinite. From these figures it can be seen that the relationship between $d_{0} / d$ and $k_{s} L / P_{e}$ is linear. These graphs can be used as a design aid to determine the required brace stiffness to attain a certain compressive strength for a given column length, brace location and desired deflection.

For instance, if one wishes to attain $90 \%$ of $P_{\text {rigid }}$ for a compression member with $\lambda=1$ and limit the additional deflection $d$ to $d_{0}$, one can draw a horizontal line from $d_{0} / d=1$ to intersect the line where $P / P_{\text {rigid }}=0.9$, and read the required $k_{s} L / P_{e}$ from the abscissa. Thus, if the brace is placed at the quarter point (i.e., $a_{1} / L=0.25$ ), the required $k_{s} L / P_{e}$ from Figure $10 \mathrm{a}$ is about 11 ; and if the brace is placed at the midpoint (i.e., $a_{1} / L=0.5$ ), the required $k_{s} L / P_{e}$ from Figure $10 \mathrm{~b}$ reduces to about 6 . Once the brace stiffness is known, the brace force can be determined from Eq. 4 . The brace can then be designed to provide the necessary stiffness and strength.

\subsection{Relationship between Brace Force $F_{s}$ and Maximum Column Strength $\boldsymbol{P}_{\max }$}

According to Eq. (4), the force in the brace $F_{s}$ is a function of the brace stiffness $k_{s}$ and the lateral deformation $d$ of the column. Because a stiff brace tends to reduce the lateral deformation of the column and vice versa, the brace force may increase or decrease with brace stiffness. The mathematical relationship between the brace force and the maximum column strength is rather complex and highly nonlinear. In Figure 11, the envelope curves for the ratio of brace force to maximum column strength $F_{s} / P_{\max }$ is plotted against the nondimensional brace stiffness $k_{s} L / P_{e}$ for the range of data used in the study (i.e., $0.5 \leq \lambda \leq 4,0.125 \leq a_{1} / L \leq 0.5$, and $6 \leq k_{s} L / P_{e} \leq 100$ ). From the figure, it can be seen that an upper bound value for $F_{s} / P_{\max }$ can be taken as $4 \%$. Thus, for design purpose a $F_{S} / P_{\max }$ value of $4 \%$ can be used. This value is higher than $2 \%$ normally assumed for $F_{s} / P_{\text {max }}$. However, it should be pointed out this $2 \%$ rule was based on elastic response of the column under service load. As was demonstrated in Figures 8a and b, additional deflection will result at or near $P_{\max }$ for an inelastic column, hence a higher brace force is justified in the context of a limit state design.

\section{DESIGN RECOMMENDATION}

In a conventional design of a braced compression member, the member is assumed to be fully braced (i.e., the braced point is assumed to undergo no lateral displacement). The design strength of the member is calculated based on the compressive strength of the longest segment of the member assuming an inflection point occurs at the brace point. However, as pointed out earlier, if the brace stiffness is finite the fully braced condition can be realized only for a centrally braced geometrically perfect pinned-pinned column. For other cases, lateral deflection will occur at the brace point, and the compressive strength of the member will be lower than its assumed fully-braced condition. The exact relationship between column capacity, brace stiffness, brace location, and brace deflection is rather complex. For design purpose, the use of simplified equations is desirable. If the design objective is for the column to develop at least $90 \%$ of its theoretical fully-braced strength (i.e., if $P / P_{\text {rigid }}$ is $\geq 90 \%$ ), a design equation can be proposed as: 


$$
k_{s, r e q^{\prime} d}=\frac{P_{e}}{\left(0.08+0.436 \lambda^{-2.15}\right) \cdot a_{1}}\left(0.7+\frac{d_{0}}{d}\right)
$$

In the above equation, $P_{e}=\pi^{2} E I /(K L)^{2}$ is the elastic buckling strength of the column without using the fully-braced assumption, $K L$ is the effective length, $\lambda=K L / \pi r\left(\sqrt{ } F_{y} / E\right)$ is the slenderness parameter, $a_{1}$ is the location of the brace measured from the nearest external pinned support or internal inflection point of the column, $d_{0}$ and $d$ are the initial out-of-straightness and additional lateral deflection of the column, respectively.

For comparison purposes, Eq. 9 is plotted in Figure 10 as a dashed line in each case. It is also plotted in Figure 12 for a slender (elastic) column braced at midpoint for which the theoretical solution is given by Timoshenko and Gere [15]. As can be seen, the equation gives value for the required brace stiffness that allows at least $90 \%$ of the theoretical fully-braced strength of the column to be developed.

\subsection{Design Procedure}

The following procedure is recommended for the design of a braced column:

1. Assuming a fully-braced condition (i.e., assuming that no lateral movement occurs at the braced point), select a section so that $\phi_{c} P_{n}>P_{u}$, where $\phi_{c} P_{n}$ is the design strength of the segment of the compression member with the largest $K L$ value, in which $\phi_{c}=0.90$ is the resistance factor as per ANSI/AISC 360-05 [27], and $P_{u}$ is the required strength of the column.

2. Since the fully-braced condition is not attainable for a brace with finite brace stiffness, the actual design strength is less than its calculated value. However, a brace can be designed to assure that at least $90 \%$ of this design strength can be attained to resist the applied load. This can be done by specifying a $d_{0} / d$ ratio, and compute the required brace stiffness $k_{s}$ from Eq. 9.

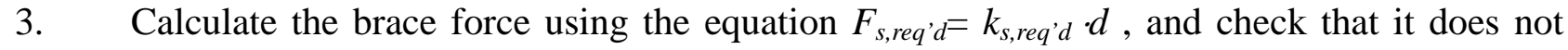
exceed $4 \%$ of the design compressive strength of the column.

4. Design the brace so that its stiffness $k_{s}$ and strength $F_{s}$ exceed their respectively required values.

5. Check that the actual design strength, which is equal to at least $90 \%$ of its code specified value, does not exceed the required strength, i.e., make sure $0.90 \phi_{c} P_{n} \geq P_{u}$.

\subsection{Design Examples}

Example 1: Determine the required stiffness and force of a brace required to brace the column shown in Figure 13 so that it can withstand an axial force of 1400 kips (6230 kN). The column is a W14x132 section made of A992 steel ( $F_{y}=50 \mathrm{ksi}$ or $345 \mathrm{MPa}$ ). It is 16-ft (4.9-m) long, pinned at both ends, and braced against weak axis instability at a location shown in the figure. The column is assumed to have an initial out-of-straightness in the form of Eq. 8 with $d_{0, \max }=0.001 \mathrm{~L}$. The additional deflection of the column $d$ at the brace point is not to exceed $d_{0}$. 
Solution: According to ANSI/AISC [27], the design compressive strength for flexural buckling of members without slender elements is

$$
\phi_{c} P_{n}=\phi_{c} F_{c r} A_{g}
$$

where $\phi_{c}=0.90$ is the resistance factor for compression, $A_{g}$ is the gross cross-section area, and $F_{c r}$ is the critical buckling stress given by

$$
F_{c r}= \begin{cases}\left(0.658^{\frac{F_{y}}{F_{e}}}\right) F_{y}, & \frac{K L}{r} \leq 4.71 \sqrt{\frac{E}{F_{y}}} \\ 0.877 F_{e}, & \frac{K L}{r}>4.71 \sqrt{\frac{E}{F_{y}}}\end{cases}
$$

in which $F_{e}=\pi^{2} E /(K L / r)^{2}$ is the elastic buckling stress, $F_{y}$ is the yield stress, $E$ is the modulus of elasticity, $K L$ is the effective length, and $r$ is the radius of gyration.

For the W14×132 section, $A_{g}=38.8 \mathrm{in}^{2}\left(250 \mathrm{~cm}^{2}\right), r_{x}=6.28 \mathrm{in} .(16 \mathrm{~cm}), r_{y}=3.76 \mathrm{in}$. $(9.55 \mathrm{~cm})$, and if we assume fully-braced condition, $(K L)_{\mathrm{x}}$ and $(K L)_{\mathrm{y}}$ are equal to $192 \mathrm{in.}(488 \mathrm{~cm})$ and $144 \mathrm{in}$. (366 $\mathrm{cm})$, respectively. By using Eqs. 10 and 11, we have $\left(\phi_{c} P_{n}\right)_{\mathrm{x}}=1630 \mathrm{kips}(7250 \mathrm{kN})$ and $\left(\phi_{c} P_{n}\right)_{\mathrm{y}}=1570 \mathrm{kips}(6980 \mathrm{kN})$.

By comparing $\left(\phi_{c} P_{n}\right)_{\mathrm{x}}$ with $\left(\phi_{c} P_{n}\right)_{\mathrm{y}}$, it can be seen that $\left(\phi_{c} P_{n}\right)_{\mathrm{y}}$ controls. However, it should be noted that the computed $\left(\phi_{c} P_{n}\right)_{\mathrm{y}}$ value assumes a fully-braced condition, which is not attainable in real life. As a result, we need to use Eq. 9 to calculate the required brace stiffness $k_{s, \text { req'd }}$ to ensure that at least $90 \%$ of this computed $\left(\phi_{c} P_{n}\right)_{\mathrm{y}}$ value can be achieved, and that this value is still larger than the required compressive strength $P_{u}=1400$ kips $(6230 \mathrm{kN})$.

For a non fully-braced condition, $(K L)_{y}=192$ in. $(488 \mathrm{~cm})$. Substituting $P_{e}=P_{e y}=\pi^{2} E I_{y} /(K L)_{\mathrm{y}}{ }^{2}=$ 4255 kips $(18930 \mathrm{kN}), \lambda=(K L / \pi r)_{y}\left(\sqrt{F_{y}} / E\right)=0.675, a_{1}=48$ in. $(122 \mathrm{~cm})$ and $d_{0} / d=1$ into Eq. 9 , we obtain $k_{s, \text { req' } d}=138 \mathrm{k} / \mathrm{in}$. $(241 \mathrm{kN} / \mathrm{cm})$. By substituting $d=d_{0}=0.001 L \cdot \sin (\pi / 4)=0.136$ in. (3.45 mm) into Eq. 4, we obtain $F_{s, \text { req'd }}=18.8$ kips $(83.6 \mathrm{kN})$.

If the brace is designed to have a stiffness of $138 \mathrm{k} / \mathrm{in}$. $(241 \mathrm{kN} / \mathrm{cm})$ and can withstand a force of 18.8 kips $(83.6 \mathrm{kN})$, the designed compressive strength about the weak axis will be at least $90 \%$ of its calculated code-specified strength, i.e., $0.90\left(\phi_{c} P_{n}\right)_{\mathrm{y}}=0.90(1570 \mathrm{kips})=1413 \mathrm{kips}(6285 \mathrm{kN})$. Since this value exceeds the required strength $P_{u}$ of $1400 \mathrm{kips}(6230 \mathrm{kN})$, and because $F_{s} / P_{\max }=$ $F_{s} / 0.90\left(\phi_{c} P_{n}\right)_{\mathrm{y}}=1.3 \%$, which is less than $4 \%$, the design is considered acceptable.

Example 2: Repeat Example 1 if the top end of the column is now fixed against rotation, and the axial force that needs to be carried is 1450 kips (6452 kN).

Solution: The pinned-fixed column can be transformed into an equivalent pinned-pinned column through the use of the effective length factor $K$. In theory, the $K$ factor for this case is 0.7. However, ANSI/AISC [27] recommends a value of 0.8 since a full fixity rarely occurs in real life. Assuming a fully-braced condition, we have $(K L)_{\mathrm{x}}=154 \mathrm{in}$. $(390 \mathrm{~cm})$, and $(K L)_{\mathrm{y}}=115 \mathrm{in}$. (293 $\mathrm{cm})$. From Eqs. 10 and 11, we have $\left(\phi_{c} P_{n}\right)_{\mathrm{x}}=1670 \mathrm{kips}(7430 \mathrm{kN})$ and $\left(\phi_{c} P_{n}\right)_{\mathrm{y}}=1630 \mathrm{kips}(7250$ $\mathrm{kN})$. Again, we can see that the design is controlled by weak axis buckling. 
Now, to correct for the non fully-braced condition, we use Eq. 9 with $P_{e}$ and $\lambda$ computed using $(K L)_{y}=(0.8)(192 ”)=154$ in. $(391 \mathrm{~cm})$. The result is $k_{s, r e q ' d}=138.7 \mathrm{k} / \mathrm{in} .(243 \mathrm{kN} / \mathrm{cm})$. From Eq. 4, $F_{s}=17.7 \mathrm{k}(78.7 \mathrm{kN})$, which is less than $4 \%$ of $0.90\left(\phi_{c} P_{n}\right)_{\mathrm{y}}=0.04 \times(0.90)(1630)=58.7 \mathrm{kips}(261$ $\mathrm{kN})$. Since $0.90\left(\phi_{c} P_{n}\right)_{\mathrm{y}}=1467 \mathrm{k}(6525 \mathrm{kN})$ still exceeds $P_{u}=1450 \mathrm{k}(6450 \mathrm{kN})$, the $\mathrm{W} 14 \times 132$ section is acceptable.
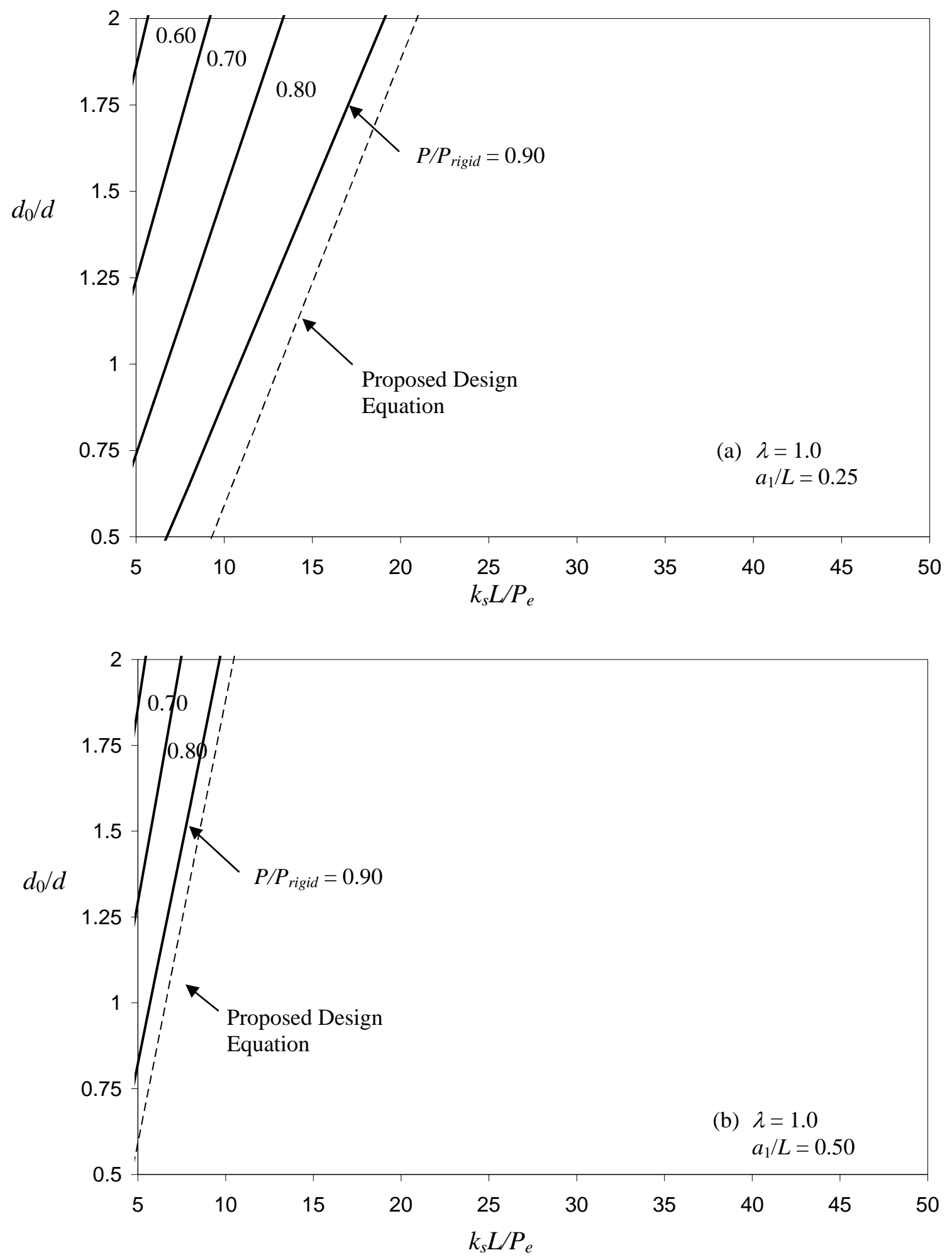

Figure 10. Relationship between Brace Stiffness and Deflection Ratio for a Given $P / P_{\text {rigid }}$ 

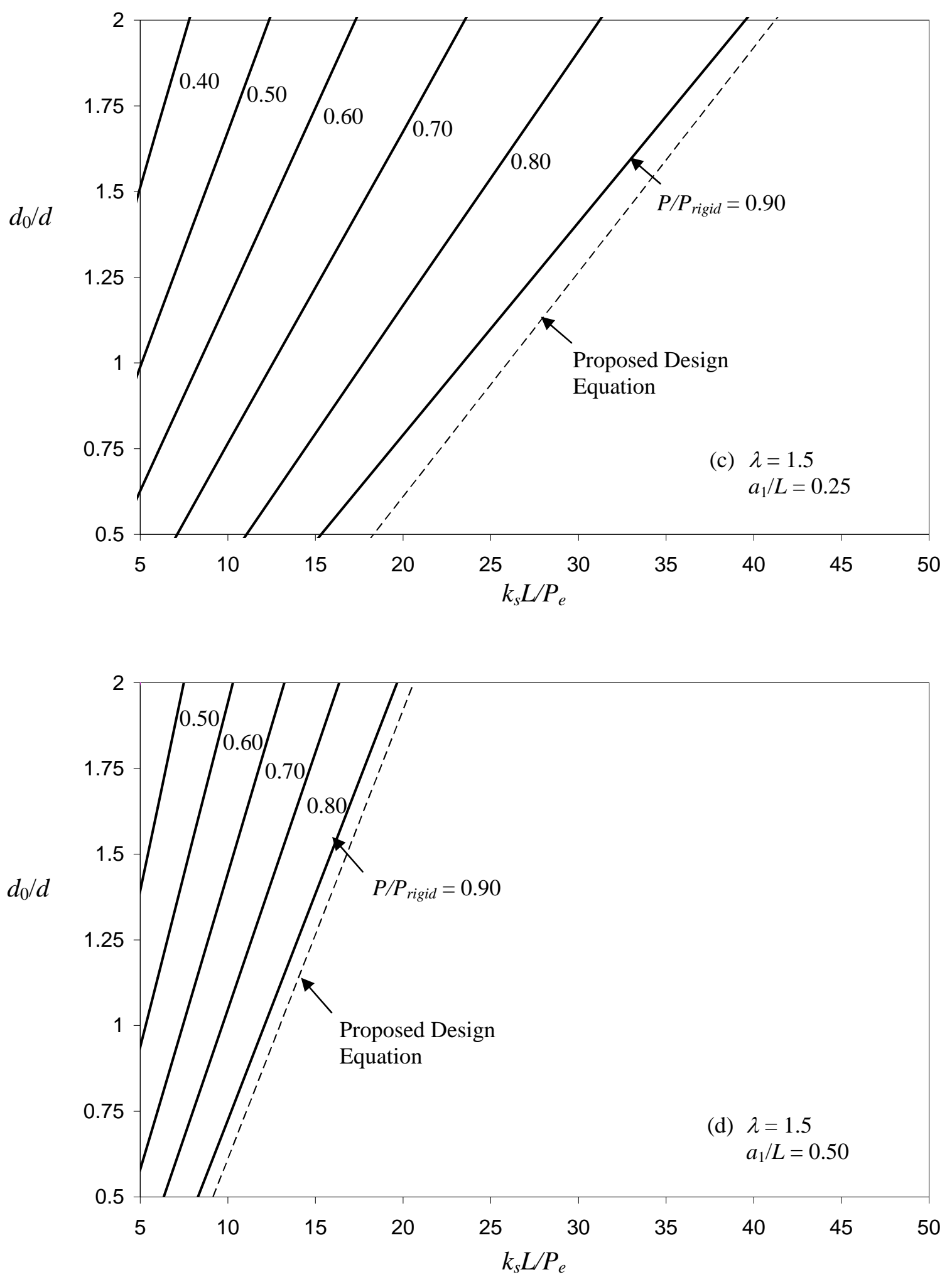

Figure 10 (Cont'd). Relationship between Brace Stiffness and Deflection Ratio for a Given $P / P_{\text {rigid }}$ 

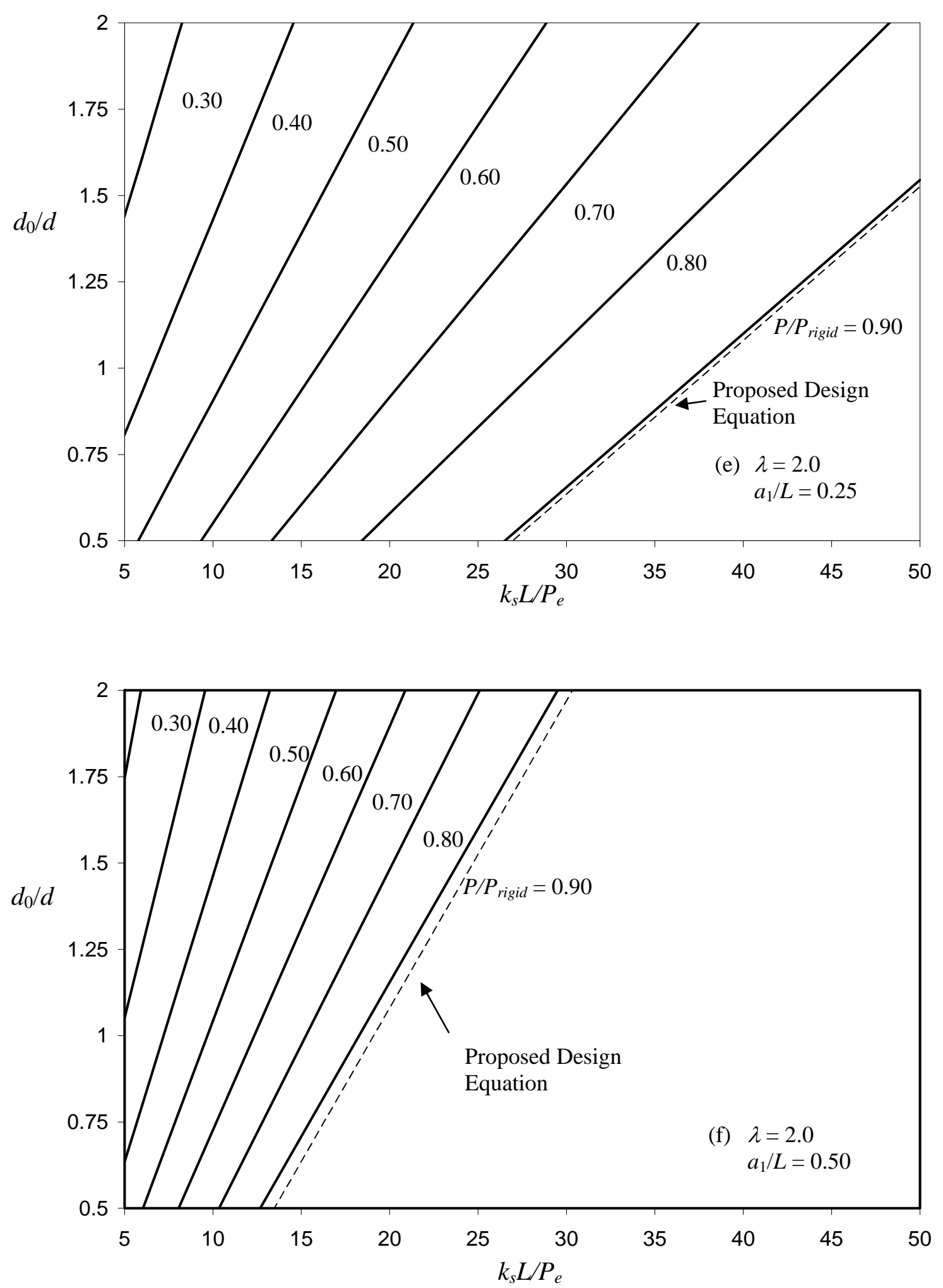

Figure 10 (Cont’d). Relationship between Brace Stiffness and Deflection Ratio for a Given $P / P_{\text {rigid }}$ 


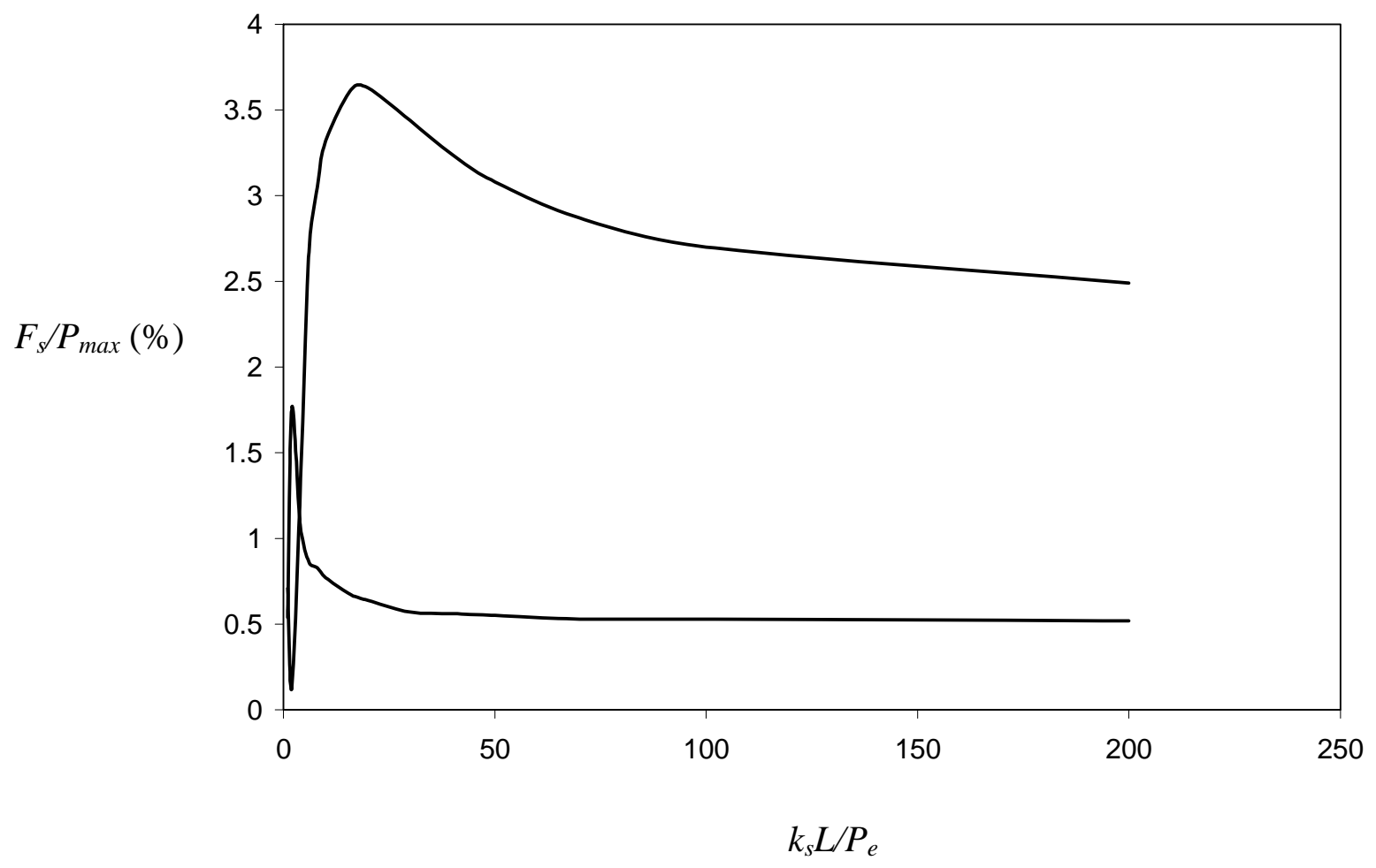

Figure 11. Envelope Curves for Brace Force

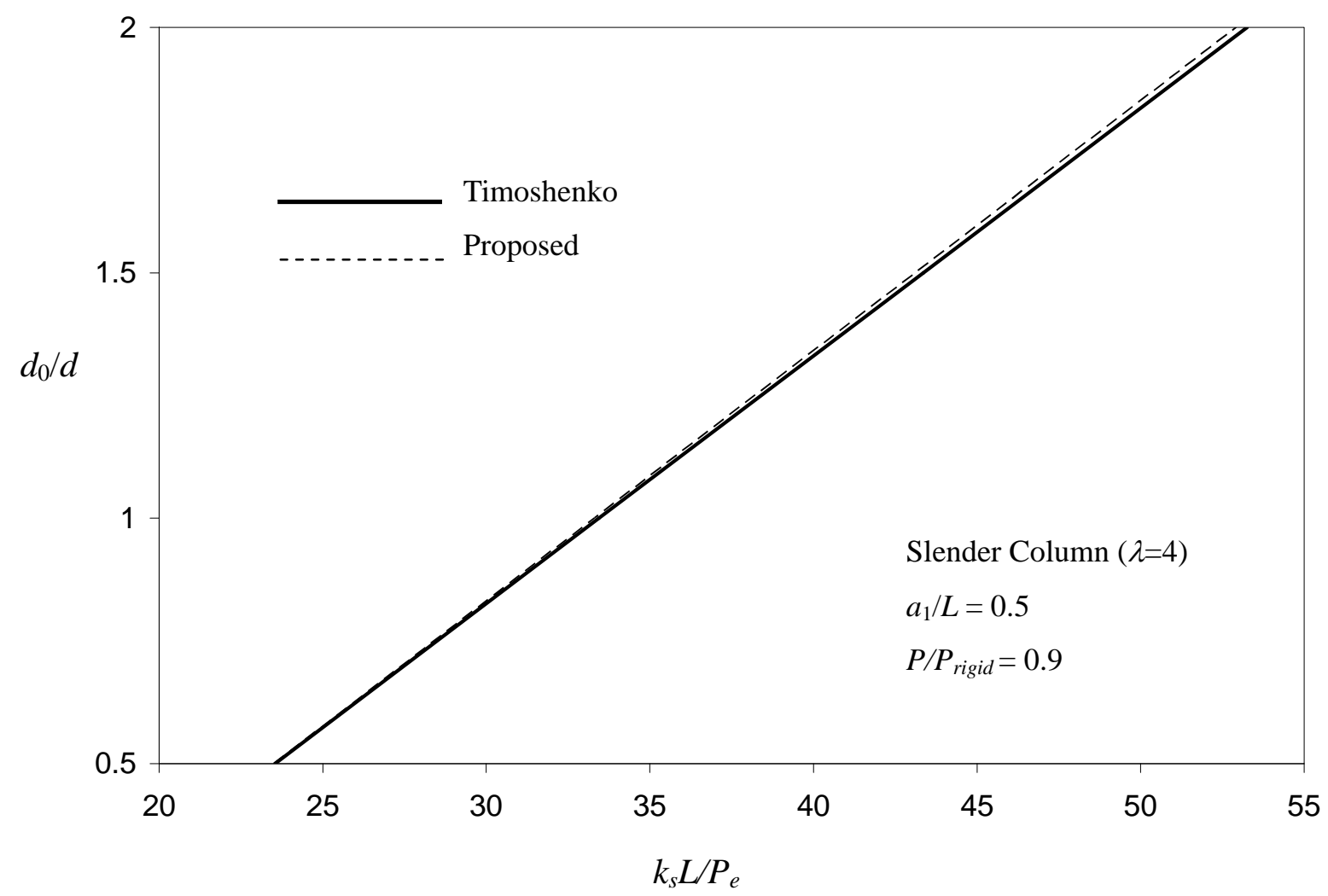

Figure 12. Comparison of Proposed Equation with Timoshenko’s Solution 


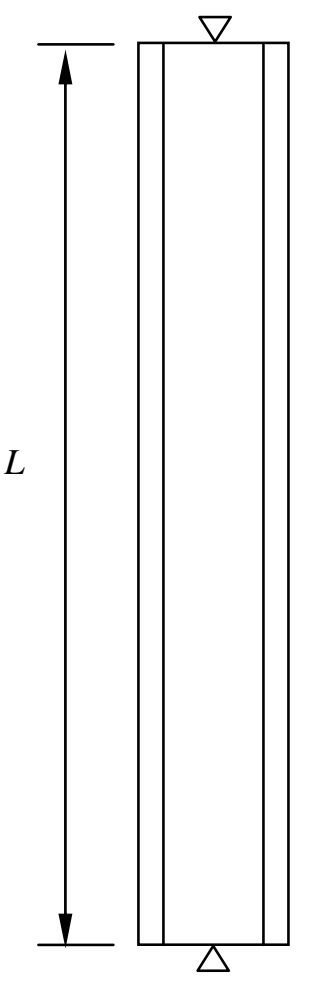

Strong Axis
Buckling

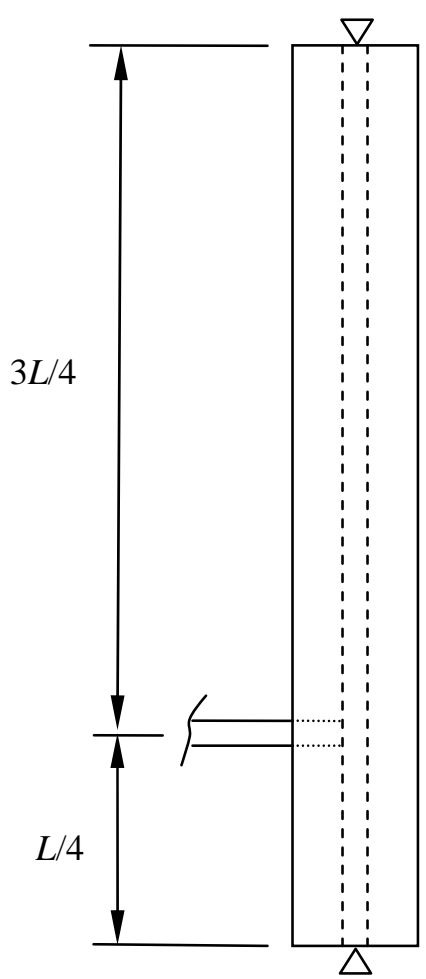

Weak Axis

Buckling

Figure 13. Example Problems

\section{SUMMARY}

In the conventional design of compression members braced against instability at some intermediate point, the practice is to assume that the brace is rigid and it does not undergo any deformation. As a result, the member being braced is assumed not to experience any lateral displacement at the location of the brace and can attain its fully-braced strength. In reality, this so-called fully-braced condition can only be realized if the brace is infinitely stiff. If the brace has a finite stiffness or if the compression member being braced is geometrically imperfect, the actual design compressive strength of the column will be less than its code-specified value. In this paper, the behavior of compression members with finite brace stiffness taking into considerations geometrical imperfection and inelastic effects was investigated. Based on the results of this study, the following conclusions can be drawn:

1. The brace is the most effective when it is placed at a point along the length of the column where maximum lateral deflection occurs at incipient instability.

2. The effect of the brace on the design compressive strength is less pronounced for short columns.

3. The concept of ideal brace stiffness applies only to a centrally braced pinned-pinned column. 
4. When compared to the fully-elastic condition, the required force and stiffness of the brace increases once inelasticity sets in. For design purpose, the maximum brace force can be taken as $4 \%$ of the braced column strength.

5. The mathematical form of the initial out-of-straightness of the column is not an important design parameter as it has very little effect on the behavior of the braced column.

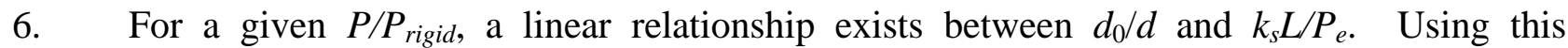
information, a design equation for $k_{s}$ that allows a braced member to reach at least $90 \%$ of its fully-braced (i.e., code-specified) strength is proposed.

\section{ACKNOWLEDGMENT}

The authors would like to thank the reviewers of this paper for their insightful comments and helpful suggestions. Their valuable inputs have helped us further address or clarify some of the concepts presented in this paper.

\section{REFERENCES}

[1] Bleich, F., "Buckling Strength of Metal Structures”, McGraw-Hill, NY, 1952.

[2] Bjorhovde, R., "Deterministic and Probabilistic Approaches to the Strength of Steel Columns,” Ph.D. Dissertation, Lehigh University, Bethlehem, PA, 1972.

[3] Galambos, T.V. ed., "Guide to Stability Design Criteria for Metal Structures”, 5" edition, John Wiley and Sons, NY, 1998.

[4] Winter, G., "Lateral Bracing of Columns and Beams,” J. of Struct. Div., Proc. ASCE, 1958, Vol. 84, No. 2, pp. 1561-1-1561-22.

[5] Timoshenko, S. and Gere, J.M., "Theory of Elastic Stability”, McGraw-Hill, NY, 1961.

[6] Urdal, T.B., "Bracing of Continuous Columns,” Engrg, J., AISC, 1969, Vol. 6, No. 3, pp. 80-83.

[7] Mutton, B.R. and Trahair, N.S., "Stiffness Requirements for Lateral Bracing," J. Struct. Engrg., ASCE, 1973, Vol. 99, No. 10, pp. 2167-2182.

[8] Brush, D.O. and Almroth, B.O., "Buckling of Bars, Plates and Shells”, McGraw-Hill, NY, 1975.

[9] Trahair, N.S. and Nethercot, D.A., "Bracing Requirements in Thin-Walled Structures,” in Developments in Thin-Walled Structures, Vol. 2, (J. Rhodes and A.C. Walker, editors), Elsevier, London, 1984, pp. 93-130.

[10] Lutz, L.A. and Fisher, J.M., "A Unified Approach for Stability Bracing Requirements," Engrg. J., AISC, 1985, Vol. 22, No. 4, pp. 163-167.

[11] Nair, R.S., "Forces on Bracing Systems,” Engrg. J., AISC, 1992, Vol. 29, No. 1, pp. 45-47.

[12] Plaut, R.H., "Requirements for Lateral Bracing of Columns with Two Spans," J. Struct. Engrg., ASCE, 1993, Vol. 119, No. 10, pp. 2913-2931.

[13] Plaut, R.H. and Yang, J.-G., "Lateral Bracing Forces in Columns with Two Unequal Spans," J. Struct. Engrg., ASCE, 1993, Vol. 9, No. 10, pp. 2896-2911.

[14] Zhang, H.-Y., Beliveau, J.-G., and Huston, D.R., "Minimum Lateral Stiffness for Equally Spaced Braces in Columns,” J. Engrg. Mech., ASCE, 1993, Vol. 119, No. 9, pp. 1888-1897.

[15] Wang, C.M. and Nazmul, I.M., "Buckling of Columns with Intermediate Elastic Restraint," J. Engrg. Mech., ASCE, 2003, Vol. 129, Issue 2, pp. 241-244.

[16] Pincus, G., “On the Lateral Support of Inelastic Columns,” Engrg. J., AISC, 1964, Vol. 1, No. 4, pp. 113-115. 
[17] Kitipornchai, S. and Finch, D.L., "Stiffness Requirements for Cross-Bracing," J. Struct. Engrg., ASCE, 1986, Vol. 112, No. 12, pp. 2702-2707.

[18] Ales, J.M, Jr. and Yura, J.A., "Bracing Design for Inelastic Structures,” Is Your Structure Suitably Braced, SSRC, 1993, pp. 29-37.

[19] Clarke, M.J. and Bridge, R.Q., "Bracing Force and Stiffness Requirements to Develop the Design Strength of Columns,” Is Your Structure Suitably Braced, SSRC, 1993, pp. 175-86.

[20] Gil, H. and Yura, J.A., "Bracing Requirements of Inelastic Columns,” J. of Constructional Steel Research, 1999. Vol. 51, pp. 1-19.

[21] Yura, J.A., "Winter’s Bracing Approach Revisited,” Engineering Structures, 1996, Vol. 18, No. 10, pp. 821-825.

[22] McGuire, W., "Steel Structures”, Prentice-Hall, Englewood Cliff, NJ, 1968.

[23] Salmon, C.G. and Johnson, J.E., "Steel Structures - Design and Behavior", 4 ${ }^{\text {th }}$ edition, HarperCollins, NY, 1996.

[24] CSA, Limit States Design of Steel Structures, CSA Standard CAN/CSA S16-01, Canadian Standards Association, Mississauga, Ontanio, 2001.

[25] Stanway, G.S., Chapman, J.C., and Dowling, P.J., “A Simply-Supported Column with a Transverse Elastic Restraint at any Position. Part 1: Behavior; Part 2: Design Models," Proc. Instn. Civ. Engrs, Strucs. and Bldgs, 1992, Vol. 94, No. 2, pp. 205-228

[26] Lui, E.M. and Zhang, C.-Y., "Nonlinear Frame Analysis by the Pseudo Load Method," Comp. and Struct., 1990, Vol. 37, No. 5, pp. 707-716.

[27] ANSI/AISC 360-05, "Specification for Structural Steel Buildings, American Institute of Steel Construction”, Chicago, IL, 2005. 